\title{
Dr. Robert L. Kay
}

\section{Joseph A. Rard ${ }^{1} \cdot$ W. Earle Waghorne ${ }^{2}$}

Published online: 21 November 2018

(c) Springer Science+Business Media, LLC, part of Springer Nature 2018

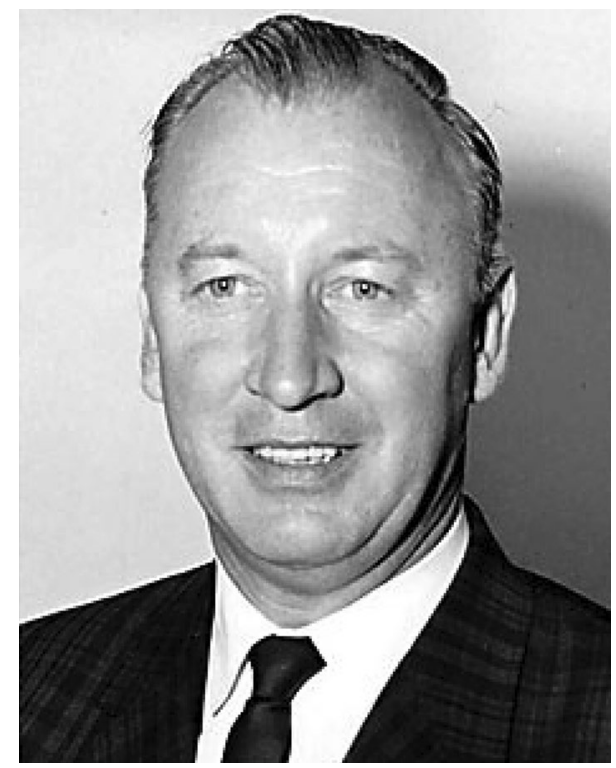

Dr. Robert L. Kay, 1924-2018

Dr. Robert L. Kay, the founding editor and sole editor of Journal of Solution Chemistry from 1972 through June 2003, passed away on 27 June 2018 at the age of 93. Bob Kay was born In Hamilton, Ontario (Canada), received his B.A. in Chemistry from St. Michael's College in Toronto and his M.A. and Ph.D. (in 1952), also in Chemistry, from University of Toronto.

Joseph A. Rard

solution_chemistry2@comcast.net

1 Livermore, CA, USA

2 University College Dublin, Dublin, Ireland 
From 1952 to 1956 Bob Kay was a Postdoctoral Fellow and then Research Assistant at the Rockefeller Institute for Medical Research and from 1956 to 1963 was an Assistant Professor at Brown University in Province, Rhode Island. In 1963 he moved to the Mellon Institute of Industrial Research in Pittsburgh as a Senior Fellow, and in 1967, when the Mellon Institute of Industrial Research merged with Carnegie Institute of Technology to become Carnegie Mellon University, he was appointed Professor of Chemistry. He spent the rest of his professional career at Carnegie Mellon University, except for 1983 when he was a Visiting Professor at University of Regensberg, Germany. He was head of the Chemistry Department at Carnegie Mellon University from 1974 to 1983, and retired in 1990. In addition to mentoring his own numerous graduate students and postdoctoral students at Carnegie Mellon University, he co-mentored four Ph.D. students at the University of Pittsburgh. He was also very active with conferences on solution chemistry, in particular the IUPAC conferences on non-aqueous solutions and solute-solvent interactions.

The research of Bob Kay and his students is well known in the field of solution chemistry, especially in the areas of transport properties in both single and mixed solvents and dielectric constant measurements, e.g. Refs. [1-13].

Acknowledgements The editors thank Jocelyn Duffy, Associate Dean for Communications, Carnegie Mellon University for providing the photograph of Dr. Robert L. Kay and for providing information about his professional career. Her obituary of Dr. Kay can be found at https://www.cmu.edu/mcs/news-event s/2018/0629_Kay-Obituary.html.

\section{References}

1. Vidulich, G.A., Kay, R.L.: The dielectric constant of water between $0^{\circ}$ and $40^{\circ}$. J. Phys. Chem. 66, 383 (1962)

2. Kay, R.L., Dye, J.L.: The determination of the electrophoretic contribution to conductance from the concentration dependence of transference numbers. Proc. Natl. Acad. Sci. U.S.A. 49, 5-11 (1963)

3. Kay, R.L., Evans, D.F.: The conductance of the tetraalkylammonium halides in deuterium oxide solutions at $25^{\circ}$. J. Phys. Chem. 69, 4216-4221 (1965)

4. Kay, R.L., Vidulich, G.A., Fratiello, A.: A potentiometric method of detecting moving boundaries in the determination of transference numbers. Instrum. Sci. Technol. 1, 361-382 (1969)

5. Kay, R.L., Pribadi, K.S., Watson, B.: Determination of the pressure dependence of transference numbers. J. Phys. Chem. 74, 2724-2726 (1970)

6. Fratiello, A., Kay, R.L.: Transference numbers for $\mathrm{KCl}$ in ethanol-water and dioxane-water mixtures at $25^{\circ}$ C. J. Solution Chem. 3, 857-864 (1974)

7. Srinivasan, K.R., Kay, R.L.: Structural considerations from dielectric measurements on the aliphatic alcohols. J. Solution Chem. 4, 299-310 (1975)

8. Broadwater, T.L., Kay, R.L.: The temperature coefficient of conductance for the alkali metal, halide, tetraalkylammonium, halite, and perhalate ions in $\mathrm{D}_{2} \mathrm{O}$. J. Solution Chem. 4, 745-762 (1975)

9. Kay, R.L., Broadwater, T.L.: Solvent structure in aqueous mixtures. III. Ionic conductances in ethanolwater mixtures. J. Solution Chem. 5, 57-76 (1976)

10. Srinivasan, K.R., Kay, R.L.: The pressure dependence of the dielectric constant and density of acetonitrile at three temperatures. J. Solution Chem. 6, 357-367 (1977)

11. Wu, Y.C., Koch, W.F., Hamer, W.J., Kay, R.L.: An update on the electrical conductivity values for the primary standard $\mathrm{KCl}$ solutions: conversion to the ITS-90 temperature scale. J. Solution Chem. 19, 1053-1054 (1990)

12. Justice, M.-C., Justice, J.-C., Kay, R.L.: A conductance investigation of $\mathrm{HCl}$ in aqueous solutions of tetrahydrofuran, dimethoxyethane and dioxane. J. Solution Chem. 19, 1211-1224 (1990)

13. Bezman, R.D., Casassa, E.F., Kay, R.L.: The temperature dependence of the dielectric constants of alkanols. J. Mol. Liq. 73-74, 397-402 (1997) 